\title{
Real Life Working Shift Assignment Problem
}

\author{
San-Nah Sze ${ }^{\text {,a) }}$, Yeek-Ling Kwek, ${ }^{\text {lb) }}$, Wei-King Tiong, ${ }^{\text {,c) }}$ and Kang-Leng Chiew, ${ }^{\text {,d) }}$ \\ ${ }^{1}$ Department of Computational Science and Mathematics, \\ Faculty of Computer Science and Information Technology, Universiti Malaysia Sarawak, \\ 94300 Kota Samarahan, Sarawak, Malaysia \\ a) Corresponding author: psnsze@unimas.my \\ b) ddling_duck315@hotmail.com, ${ }^{\text {c) }}$ wktiong@unimas.my, ${ }^{\text {d) }}$ klchiew@unimas.my
}

\begin{abstract}
This study concerns about the working shift assignmelnt in an outlet of Supermarket X in Eastern Mall, Kuching. The working shift assignment needs to be solved at least once in every month. Current approval process of working shifts is too troublesome and time-consuming. Furthermore, the management staff cannot have an overview of manpower and working shift schedule. Thus, the aim of this study is to develop working shift assignment simulation and propose a working shift assignment solution. The main objective for this study is to fulfill manpower demand at minimum operation cost. Besides, the day off and meal break policy should be fulfilled accordingly. Demand based heuristic is proposed to assign working shift and the quality of the solution is evaluated by using the real data.
\end{abstract}

\section{INTRODUCTION}

Working shift assignment is a process of scheduling the workers in an organization for a given time. Working shift assignment is an important task that needs to be solved in many industries. This assignment problem normally needs to be carried out weekly or monthly depending on the company cultural. The working shift can be assigned by management level in the organization such as supervisor and head of department. However, companies that have two or three working shift per day and employ mixture of part-timer, permanent staff and contract staff face a tough working shift assignment challenges.

The scheduling problem nowadays is much more complicated compared to the scheduling problem introduced by [1] and [2]. The selected papers that investigated the supermarket retail chain working shifts assignment are [3], [4] and [5].

In this project, working shift assignment problem of real life company named Supermarket $\mathrm{X}$ is studied. Supermarket $\mathrm{X}$ is one of the oldest local chains of retail supermarket in Sarawak. There are 12 well equipped and efficient outlets in Kuching and Serian. One of their outlets at Eastern Mall is investigated as our case study. This project aims to assign working shift to the staff with lowest cost and minimum number of staff.

Current approval process of working shifts at Supermarket $\mathrm{X}$ is time-consuming. The head of department needs to key in the working shift into the current system after getting the approval from human research department. Moreover, the quality of working shift assigned is hard to determine because the human resource staff will approve the working shift as long as the full shift and day off seem like equally given to all the staff. Furthermore, day off of specific staff cannot be traced. Manpower fulfillment might be overlooked and overtime of staff is hard to monitor.

The situation gets worsen when the staff might unsatisfied with the working shift assigned to them, especially full shifts assigned for continuous days. Many companies tend to purchase some open source software to schedule the working shift for the staff but usually the working shift solution cannot fit perfectly to the companies as different companies will have different considerations and constraints. Thus, a simulation model is developed to solve this case study.

\section{ORGANIZATION BACKGROUND}

The outlet of the Supermarket X has eight departments and the highest position in the supermarket is store head. The eight departments include non-food, food, fresh, bakery, RTE, cashiering, receiving clerk and operation clerk. There are 99 staff that currently work in the supermarket.

International Conference of Numerical Analysis and Applied Mathematics (ICNAAM 2016)

AIP Conf. Proc. 1863, 050017-1-050017-5; doi: 10.1063/1.4992214

Published by AIP Publishing. 978-0-7354-1538-6/\$30.00 